Augustine Chavez, MD

Assistant Professor of Family Medicine

Department of Family Medicine,

Mayo Clinic, Scottsdale, AZ
Robert Scales, PhD

Director of Cardiac Rehabilitation and

Wellness, Department of Cardiology,

Mayo Clinic, Scottsdale, AZ
Juliana M. Kling, MD, MPH

Associate Professor of Medicine, and Chair

Division of Women's Health Internal Medicine,

Mayo Clinic, Scottsdale, AZ

\title{
Promoting physical activity in older women to maximize health
}

\section{ABSTRACT}

Physical activity can maximize health by improving disease-oriented and patient-oriented outcomes in women age 60 and older. General activity levels are low in the United States. Promoting physical activity in clinical practice is limited by time constraints and knowledge deficits. Understanding the benefits of the specific type of physical activity, the intensity, and the level in older women helps clinicians provide focused, time-efficient counseling in primary care. This review details the benefits of physical activity in older women by disease state.

\section{KEY POINTS}

Sex-specific differences in diseases exist for older women.

The leading causes of disability and death in women over age 60 are cardiovascular disease, stroke, hypertension, diabetes mellitus, hyperlipidemia, cancer, cognitive decline, chronic obstructive pulmonary disease, depression, musculoskeletal disorders, osteoporosis, and falls, all of which are improved by physical activity.

Primary care counseling on routine physical activity and exercise can increase the level of activity in women age 60 and older and improve clinical outcomes.
T HE WORLD'S POPULATION is rapidly aging, 1 particularly women, who have a life expectancy 10 years longer than that of men. ${ }^{1} \mathrm{By}$ 2050 , the number of women age 60 is expected to double, and the number of women age 80 is expected to triple.

The leading causes of disability and death in women over age 60 are cardiovascular disease, diabetes mellitus, chronic obstructive pulmonary disease (COPD), cancer, back pain, arthritis, osteoporosis, falls, depression, and dementia. ${ }^{1}$ Approximately 20\% have more than one health condition. ${ }^{1}$ Improving outcomes in these conditions is crucial to health as women age.

Physical activity is a safe way to improve health and to promote healthy aging. Important differences exist between men and women in the degree of benefit derived from physical activity, especially for stroke risk, hypertension, and diabetes and, thus warrant special attention. ${ }^{2-5}$ While it is generally accepted that physical activity is a healthy behavior and that any activity is better than none, the optimal type, intensity, and level required to achieve specific health outcomes depends on the disease the patient and clinician are trying to prevent or manage.

Physical activity is defined as "any bodily movement produced by the contraction of skeletal muscle that increases energy expenditure above a basal level." Exercise is "a form of physical activity that is planned, structured, repetitive, and performed with the goal of improving health or fitness." ${ }^{2}$ The distinction between the two is important as clinical outcomes vary depending on the type, intensity, and level of activity. Definitions and examples of physical activity, with estimates of metabol- 


\section{TABLE 1}

\section{Physical activity and exercise: Definitions and durations}

Physical activity Bodily movement from skeletal muscle contraction resulting in energy expenditure above baseline.

Exercise Planned, structured, repetitive physical activity performed to improve health or fitness.

MET (metabolic equivalent A measure of energy expenditure for an activity with a of task) reference of $1 \mathrm{MET}$ being rest.

\begin{tabular}{|c|c|c|}
\hline \multirow[t]{3}{*}{ Intensity } & $\begin{array}{l}\text { Low intensity: } \\
\text { Nonsedentary activity } \leq 3 \text { METs }\end{array}$ & $\begin{array}{l}\text { Leisurely walking ( } \leq 2 \mathrm{mph} \text { ) } \\
\text { Light household chores }\end{array}$ \\
\hline & Moderate intensity: 3-5.9 METs & $\begin{array}{l}\text { Golfing (walking, carrying bag) } \\
\text { Dance } \\
\text { Pickleball } \\
\text { Brisk walk ( } 2.5-4 \mathrm{mph}) \\
\text { Gardening } \\
\text { Playing with grandchildren }\end{array}$ \\
\hline & $\begin{array}{l}\text { Vigorous intensity: } \\
\geq 6 \mathrm{METs}\end{array}$ & $\begin{array}{l}\text { Hiking } \\
\text { Swimming } \\
\text { Water aerobics } \\
\text { Fast walk ( } \geq 4.5 \mathrm{mph}) \\
\text { Stationary cycling } \\
\text { Strenuous fitness classes }\end{array}$ \\
\hline \multirow[t]{4}{*}{ Activity level } & $\begin{array}{l}\text { Inactive: No moderate to vigorous } \\
\text { physical activity }\end{array}$ & \\
\hline & Low: Almost completely inactive & \\
\hline & $\begin{array}{l}\text { Moderate: Some physical activity } \\
>4 \mathrm{hr} / \mathrm{wk} \text { or about } 12 \mathrm{MET} \text { hr/week } \\
\text { or more }\end{array}$ & $\begin{array}{l}\text { Brisk walk } 4 \mathrm{hr} / \mathrm{wk} \\
\text { Pickleball } 2.5 \mathrm{hr} / \mathrm{wk} \\
\text { Golfing (walking, with bag) } 3 \mathrm{hr} / \mathrm{wk}\end{array}$ \\
\hline & $\begin{array}{l}\text { High: Vigorous activity }>3 \mathrm{hr} / \text { week } \\
\text { or about } 18 \mathrm{MET} \text { hr/wk or more }\end{array}$ & $\begin{array}{l}\text { Hiking } 3 \mathrm{hr} / \mathrm{wk} \\
\text { Swimming } 2.5 \mathrm{hr} / \mathrm{wk} \\
\text { Strenuous fitness class } 2.5 \mathrm{hr} / \mathrm{wk}\end{array}$ \\
\hline \multirow[t]{3}{*}{ Types of exercise } & $\begin{array}{l}\text { Aerobic: Rhythmic movement of } \\
\text { large muscles for sustained periods } \\
\text { of time }\end{array}$ & $\begin{array}{l}\text { Walking } \\
\text { Swimming } \\
\text { Stationary cycling }\end{array}$ \\
\hline & $\begin{array}{l}\text { Resistance: Activity that increases } \\
\text { skeletal muscle strength, power, } \\
\text { endurance and mass }\end{array}$ & $\begin{array}{l}\text { Lifting weights } \\
\text { Using resistance bands } \\
\text { Body movement underwater }\end{array}$ \\
\hline & $\begin{array}{l}\text { Combined: Activity with aerobic } \\
\text { and resistance components }\end{array}$ & $\begin{array}{l}\text { Fitness classes with weights } \\
\text { Circuit training }\end{array}$ \\
\hline
\end{tabular}

Knowing

the type and

intensity

of activity

that benefits

each disease

helps clinicians

make specific

recommen-

dations

\begin{abstract}
Low intensity:
Inactive: No moderate to vigorous physical activity

Moderate: Some physical activity $>4 \mathrm{hr} / \mathrm{wk}$ or about $12 \mathrm{MET}$ hr/wee
\end{abstract}

Dance

Brisk walk (2.5-4 mph)

Gardening

Water aerobics

Fast walk ( $\geq 4.5 \mathrm{mph}$ )

Stationary cycling

Strenuous fitness classes

High: Vigorous activity $>3 \mathrm{hr} /$ week large muscles for sustained periods

Resistance: Activity that increases skeletal muscle strength, power,

Combined: Activity with aerobic ic equivalents, a measure of energy output, are presented in Table 1.

Levels of physical activity are low in US women, and $80 \%$ do not meet the US Department of Health and Human Services mini- mum recommendation for adults, including older adults, of at least 150 minutes a week of moderate-intensity activity or 75 minutes a week of vigorous-intensity activity. ${ }^{2}$

Evidence supports population-wide pro- 
motion of physical activity to improve health, ${ }^{2}$ yet counseling on this by primary care providers remains inadequate with only about $21 \%$ of patients receiving counseling. ${ }^{6}$ Barriers to this counseling include a lack of training and knowledge among providers on the benefits of physical activity, as well as time constraints and inadequate counseling skills. ${ }^{6}$

This review presents outcomes from systematic reviews and meta-analyses published through December 2019 that describe optimal type, intensity, and level of physical activity to improve outcomes for the most common causes of morbidity and death in women age 60 and older (Table 2)..$^{3-5,7-21}$ This information can help clinicians provide practical, specific, and time-efficient counseling in the primary care setting.

While some studies report outcomes specifically for women, most include both men and women, and thus we have generalized the combined data to women. This is discussed in more detail below in the section, "Limitations of current literature on physical activity."

\section{DISEASE-SPECIFIC FINDINGS}

\section{Cardiovascular disease}

This is the leading worldwide cause of premature death in people age 60 and older. ${ }^{1}$ Studies have shown that physical activity improves cardiovascular disease mortality rates and major cardiovascular events including myocardial infarction and stroke, the development of coronary artery disease, and most modifiable cardiovascular risk factors.

In a systematic review, Kraus et $\mathrm{al}^{7}$ found that moderate to vigorous activity significantly reduced cardiovascular disease-related mortality rates compared with inactivity, and the greater the quantity, the greater the reduction. Performing the US Department of Health and Human Services' recommended 150 minutes per week accounted for $75 \%$ of the total estimated cardiovascular disease mortality reduction associated with physical activity. In women, Sattelmair et $\mathrm{al}^{8}$ found that leisuretime physical activity reduced the risk coronary heart disease by $33 \%$.

Patient counseling suggestion. Brisk to fast walking-and even walking at moderate intensity - for about 4 hours a week may pre- vent heart disease and death from heart disease.

\section{Stroke}

Reducing stroke risk in women requires high levels of physical activity. In a meta-analysis by Diep et $\mathrm{al}^{3}{ }^{3}$ women achieving high but not moderate activity levels had a 24\% lower stroke risk than women achieving only low activity levels. For women participating in moderate vs low activity levels, the stroke risk was not significantly different (relative risk [RR] 0.99). ${ }^{3}$

Patient counseling suggestion. Fast walking or other vigorous-intensity exercise for 3 hours per week may prevent stroke.

\section{Hypertension}

Physical activity has been shown to improve blood pressure in people with and without hypertension. A systematic review by Pescatello et $\mathrm{al}^{4}$ found that in normotensive adults, increasing activity levels was associated with decreases in the incidence of hypertension. Compared with people engaging in low-level physical activity, those engaging in moderatelevel activity had an $11 \%$ reduced risk; those engaging in high-level activity had a 19\% reduced risk. Each 10 MET hour/week of physical activity, equivalent to brisk walking for 2 to 3 hours a week, was associated with an additional $6 \%$ risk reduction in incident hypertension. $^{4}$

In people with hypertension, physical activity improves blood pressure control and reduces cardiovascular disease mortality rates. Exercise has been associated with reductions of 5 to $17 \mathrm{~mm} \mathrm{Hg}$ in systolic pressure, ${ }^{4,14}$ similar to reductions achieved with pharmacotherapy. ${ }^{14}$

In women with hypertension, increasing levels of activity is associated with significant reductions in mortality regardless of the severity of hypertension. ${ }^{4,22}$ A meta-analysis by Pescatello et $\mathrm{al}^{4}$ reported that highly active women with resting systolic blood pressures of 140 to $159 \mathrm{~mm} \mathrm{Hg}$ had a 24\% relative risk reduction, while highly active women with baseline systolic pressures above $160 \mathrm{~mm} \mathrm{Hg}$ had a $27 \%$ relative risk reduction in cardiovascular mortality compared with inactive women with the same systolic pressures.

Patient counseling suggestion. Participat-

\section{Counseling by primary care practitioners in partnership with exercise professionals results in better long-term adherence to physical activity}


TABLE 2

Benefits of exercise for common causes of morbidity and death in women a

\begin{tabular}{|c|c|c|c|c|}
\hline CONDITION & INTERVENTION & END POINT & $\begin{array}{l}\text { COMPARATOR } \\
\text { GROUP }\end{array}$ & $\begin{array}{l}\text { EFFECT SIZE } \\
(95 \% \mathrm{CI})\end{array}$ \\
\hline \multirow[t]{2}{*}{ CVD } & 7.5-14.9 MET hr/wk LTPA ${ }^{7}$ & All-cause mortality & No LTPA & HR $0.68(0.66-0.69)$ \\
\hline & $150 \mathrm{~min} / \mathrm{wk} \mathrm{MVPA}^{8}$ & CHD incidence & No LTPA & RR $0.86(0.77-0.96)$ \\
\hline Stroke & High $\mathrm{PA}^{3}$ & Stroke incidence & Low level PA & RR $0.76(0.64-0.89)$ \\
\hline \multirow[t]{3}{*}{ HTN } & High $\mathrm{PA}^{4}$ & HTN incidence & Low level PA & RR $0.81(0.76-0.85)$ \\
\hline & Moderate $\mathrm{PA}^{4}$ & HTN incidence & Low level PA & RR $0.89(0.85-0.94)$ \\
\hline & Any exercise (exercise in general) ${ }^{14}$ & SBP reduction & Control & $-8.96 \mathrm{~mm} \mathrm{Hg}(-10.27$ to -7.64$)$ \\
\hline \multirow[t]{4}{*}{ Diabetes } & $150 \mathrm{~min} /$ week MVPA & Type 2 DM incidence & Inactivity & RR $0.74(0.69-0.80)$ \\
\hline & Supervised aerobic exercise ${ }^{9}$ & HbA1c reduction & No exercise & $-0.30(-0.60$ to -0.45$)$ \\
\hline & Supervised resistance exercise ${ }^{9}$ & $\mathrm{HbA} 1 \mathrm{c}$ reduction & No exercise & $-0.30(-0.38$ to -0.15$)$ \\
\hline & Combined exercise $^{9}$ & $\mathrm{HbA} 1 \mathrm{c}$ reduction & No exercise & $-0.53(-0.68$ to -0.45$)$ \\
\hline Breast cancer & High-level MVPA ${ }^{10}$ & Breast cancer incidence & Low level PA & HR $0.90(0.87-0.93)$ \\
\hline Cancer $^{b}$ & Supervised exercise ${ }^{11}$ & Health-related QOL & Control & SMD $0.48(0.16-0.81)$ \\
\hline \multirow[t]{2}{*}{$\begin{array}{l}\text { Cognitive } \\
\text { decline }\end{array}$} & Physical activity ${ }^{15}$ & $\begin{array}{l}\text { Alzheimer disease } \\
\text { incidence }\end{array}$ & Inactivity & RR $0.61(0.52-0.73)$ \\
\hline & $\begin{array}{l}\text { Moderate to high-intensity aero- } \\
\text { bic exercise } \mathrm{e}^{16}\end{array}$ & Global cognition & Control & SMD $0.60(0.21-0.98)$ \\
\hline COPD & Pulmonary rehabilitation ${ }^{17}$ & Dyspnea & Usual care & MD $0.79(0.56-1.03)$ \\
\hline Depression & $\begin{array}{l}\text { Moderate to high intensity } \\
\text { combined exercise }{ }^{18}\end{array}$ & Depression severity ${ }^{c}$ & Control & SMD $-0.34(-0.52$ to -0.17$)$ \\
\hline \multirow[t]{2}{*}{ Hip OA } & Land-based exercise ${ }^{12}$ & Pain (3-6 mo) & No exercise & SMD $-0.38(-0.58$ to -0.18$)$ \\
\hline & Land-based exercise $^{12}$ & Physical function & No exercise & SMD $-0.37(-0.57$ to -0.16$)$ \\
\hline \multirow[t]{2}{*}{ Knee OA } & Land-based exercise $^{13}$ & Pain & No exercise & SMD $-0.49(-0.39$ to -0.59$)$ \\
\hline & Land-based exercise $^{13}$ & Physical function & No exercise & SMD $-0.52(-0.39$ to -0.64$)$ \\
\hline \multirow[t]{2}{*}{ Falls } & Exercise $^{19}$ & Number of fallers & Control & RR $0.85(0.81-0.89)$ \\
\hline & Exercise $^{19}$ & Falls & Control & $\operatorname{RaR} 0.77(0.71-0.83)$ \\
\hline \multirow[t]{2}{*}{ Osteoporosis } & Combined exercise ${ }^{21}$ & $\begin{array}{l}\text { Lumbar spine bone } \\
\text { density }\end{array}$ & Usual care & SMD $0.349(0.064-0.634)$ \\
\hline & Exercise $^{20}$ & Overall fracture & No exercise & RR $0.49(0.31-0.76)$ \\
\hline
\end{tabular}

a Most studies cited here included both men and women.

${ }^{\mathrm{b}}$ Breast, colorectal, head and neck, lymphoma, others.

'Severity determined by self-report on depression scales.

$\mathrm{CHD}=$ congestive heart disease; $\mathrm{COPD}=$ chronic obstructive pulmonary disease; $\mathrm{CVD}=$ cardiovascular disease; $\mathrm{DM}=$ diabetes mellitus; $\mathrm{HbA} 1 \mathrm{c}=$ hemoglobin A1c; HR = hazard ratio; HTN = hypertension; LTPA = leisure-time physical activity; MD = mean difference; MET = metabolic equivalent of task; MVPA = moderate to vigorous physical activity; $\mathrm{OA}=$ osteoarthritis; $\mathrm{PA}=$ physical activity; $\mathrm{QOL}=$ quality of life; $\mathrm{RaR}=$ rate ratio; $\mathrm{RR}=$ relative risk; $\mathrm{SBP}=$ systolic blood pressure; SMD = standard mean difference 
ing in 2.5 hours a week of moderate-intensity exercise such as pickleball, golf, or dancing may lower blood pressure, prevent hypertension, and reduce mortality risk from heart disease in women with hypertension. Swimming 2.5 hours per week is even more beneficial as it is a vigorous-intensity exercise.

\section{Diabetes mellitus}

Diabetes is a leading cause of both morbidity and death in older people worldwide. Physical activity has been associated with significant benefits in reducing incident diabetes and in improving outcomes for diabetic patients. $5,9,23,24$

In a meta-analysis by Smith et $a 1,{ }^{5}$ higher levels and intensity of physical activity led to a lower incidence of diabetes, especially for women. Compared with inactivity, 150 minutes of moderate to vigorous activity per week reduced the risk of diabetes by $26 \%$. Long-term prospective cohort studies showed higher reductions in incident diabetes for every 10 MET hours per week of activity, equivalent to 3.5 hours of slow walking, for women compared with men (RR 0.83 vs 0.89). And more intense activity was associated with an even larger reduction in diabetes incidence. Participating in 10 MET hours per week of vigorous activity, equivalent to 100 minutes of fast walking, reduced the risk by $56 \% .^{5}$

Improvements in outcomes in patients with diabetes depended on the type and setting of exercise. Supervised exercises associated with reductions in hemoglobin A1c included aerobic exercise $(-0.30$ reduction), resistance training $(-0.30$ reduction), and combined exercise $\left(-0.53\right.$ reduction). ${ }^{9}$ However, unsupervised aerobic exercise such as walking did not improve hemoglobin A1c levels compared with no exercise at all, ${ }^{9}$ although it may prevent worsening of hemoglobin A1c levels. ${ }^{23}$

However, despite the minimal impact on hemoglobin A1c reduction, walking has been shown to benefit several patient-oriented outcomes in those with diabetes, including quality of life, sleep, vitality, physical health, and mental health. ${ }^{24}$

Patient counseling suggestion. Stationary bicycling 2 hours per week may prevent diabetes. Supervised exercise improves diabetes control.

\section{Lipids}

A systematic review found no significant reduction in levels of low-density lipoprotein (LDL) cholesterol with low-intensity or moderate-intensity exercise. ${ }^{25}$ Another review found LDL cholesterol was reduced in women engaging in resistance exercise (minus 16.2 $\mathrm{mg} / \mathrm{dL}$ ) and combined aerobic and resistance exercise (minus $23.2 \mathrm{mg} / \mathrm{dL}$ ). ${ }^{26}$ The level of high-density lipoprotein (HDL) cholesterol was increased with high-level, vigorous-intensity aerobic exercise $(4.3 \mathrm{mg} / \mathrm{dL}$ to $15.2 \mathrm{mg} /$ dL). ${ }^{26}$

Patient counseling suggestion. Resistance training with weights can lower LDL levels. Hiking 3 hours per week may raise HDL levels.

\section{Cancer}

Lung and colon cancers are 2 of the top 10 causes of death in people over age $60,{ }^{1}$ and breast cancer is the most frequent cause in women. Physical activity has been shown to reduce the incidence of cancer and improve patient-oriented outcomes such as fatigue and depression in those with cancer both during and after treatment. ${ }^{10,11,27-29}$

Compared with low levels of moderate to vigorous leisure-time activity, high levels are associated with significant reductions in the incidence of common cancers affecting women, including breast cancer (hazard ratio [HR] 0.90, 95\% confidence interval [CI] 0.87-0.93), lung cancer (HR 0.74, 95\% CI 0.71-0.77), and colon cancer (HR 0.84, 95\% CI 0.77-0.91). ${ }^{10}$ Observational studies consistently demonstrate reductions in overall and cancer-related mortality associated with increasing levels and intensity of physical activity. ${ }^{27}$

Different types of exercise are associated with benefits on patient-oriented outcomes for breast cancer survivors after treatment. Moderate- to high-intensity aerobic, resistance, and combined exercise are all associated with improvements in quality of life. ${ }^{28}$ Walking improves sleep, depression, anxiety, and cancer-related fatigue. ${ }^{29}$ Exercise, particularly if supervised by a professional, may have lasting, although small to moderate, benefits compared with usual care for improving pain, emotional well-being, social functioning,

\section{Regular moderate to vigorous activity is required for maximal benefit for many health outcomes}


sleep disturbance, and fatigue. ${ }^{11}$

Patient counseling suggestion. About 3 hours of vigorous exercise per week, such as water aerobics or fitness classes, may prevent cancer. Most exercise improves quality of life after breast cancer treatment.

\section{Cognitive decline}

Dementia is a leading cause of disability in aging populations, and the number of people living with dementia is expected to triple by 2050. ${ }^{1}$ A meta-analysis of physical activity in adults age 65 and older found it to be associated with a significant $39 \%$ reduced risk of developing dementia. ${ }^{30}$

However, exercise (as opposed to physical activity) does not appear to reduce the incidence of dementia or mild cognitive impairment. A systematic review of adults age 60 and older with normal baseline cognitive function showed no reduction in risk of dementia, mild cognitive impairment, or cognitive decline associated with exercise for longer than a year. ${ }^{15}$ Another review analyzed the effect of activities with combined physical and cognitive components, such as line dancing and tai chi, that require body motion and memorization

Even low-level, low-intensity physical activity has benefits of sequences of movement. ${ }^{31}$ Results showed that combined physical and cognitive activities improved cognitive function compared with control and physical activity alone, but not compared with cognitive activities such as computer-based games, memorization, and visual search tasks alone, suggesting that cognitive activity is the primary driver of the observed benefit.

In patients with known cognitive decline, including mild cognitive impairment and dementia, systematic reviews have found variable outcomes of exercise on quality of life. A systematic review by Law et al found that exercise of moderate to high intensity significantly reduced cognitive decline by $40 \%$ (mean age 68 to 86) but had minimal effect on behavioral problems such as agitation. ${ }^{32}$ Another systematic review found no benefit to exercise programs on either cognition or depression in patients with dementia. ${ }^{16}$ Home-based walking programs in patients with dementia showed improvements in patient-oriented outcomes including behavioral symptoms, activities of daily living, health-related quality of life, and caregiver burden..$^{33}$

Patient counseling suggestion. Physical activity may prevent dementia, but exercise likely does not. Brisk walking may slow the progression of dementia and improve quality of life.

\section{Chronic obstructive pulmonary disease}

COPD is the third leading cause of disability and death in the aging population worldwide. ${ }^{1}$ A review comparing functional and psychological outcomes in patients with COPD over age 64 found similar benefits in both sexes. ${ }^{34}$ A meta-analysis of 8 studies $^{35}$ found that the benefits of exercise in COPD are primarily from formal pulmonary rehabilitation programs, which improve functional outcomes and quality of life, but the programs may be underused in women. For those over age 60, pulmonary rehabilitation improved forced expiratory volume in 1 second, 6-minute walk distance, health-related quality of life, perceived dyspnea, and physical and emotional impacts of COPD measured by the Chronic Respiratory Questionnaire score.

Dyspnea is most consistently improved by formal pulmonary rehabilitation but not by other forms of physical activity. A Cochrane review found that hospital-based pulmonary rehabilitation improved dyspnea by $21 \%$ in patients with COPD. ${ }^{36}$ Some evidence suggests home-based pulmonary rehabilitation can improve health-related quality of life, fatigue, and 6-minute walk distance. ${ }^{17}$ Types of exercise other than pulmonary rehabilitation can improve functional outcomes but not dyspnea. Active mind-body movement therapy with tai chi improved forced expiratory volume in 1 second and 6-minute walk distance compared with usual care, ${ }^{37}$ and therapy with yoga, tai chi, or qigong improved quality of life compared with pulmonary rehabilitation. ${ }^{38}$

Patient counseling suggestion. Formal pulmonary rehabilitation improves shortness of breath, and active mind-body exercise improves quality of life in patients with COPD.

\section{Depression}

Depression is the fourth leading cause of disability in those over age 60. ${ }^{1}$ In general, highquality trials of physical activity in patients of all ages with depression have shown no significant effect compared with control groups, 
medications, or therapy. ${ }^{39}$ In patients over age 60 , however, exercise has shown consistent positive effects. ${ }^{18,40,41}$

In a systematic review of predominantly women age 60 and older with clinical depression, ${ }^{40}$ mixed moderate-intensity and high-intensity exercise was associated with significant reductions in the severity of depressive symptoms (standard mean difference [SMD] -0.34). The observed effect size was similar to that with prescription medications and was correlated with a $20 \%$ reduction in total symptom burden. In another systematic review, ${ }^{18}$ the reduction of depressive symptoms was more robust (SMD -0.61, 95\% CI -0.88 to -0.33$)$. Furthermore, the benefits of exercise on older patients with depression occurred even in patients not responsive to medications. ${ }^{41}$

Patient counseling suggestion. Fitness classes using weights improves depression symptoms as much as medications.

\section{Musculoskeletal disorders}

The combination of osteoarthritis and back pain is the leading cause of disability worldwide. ${ }^{1}$ A systematic review found low-quality evidence that in women age 65 and older with more than 6 weeks of low back pain, physical therapy is associated with small to moderate pain reduction and small improvement in function. ${ }^{42}$ High-quality evidence of the benefits of exercise exists for hip and knee osteoarthritis. ${ }^{12,13}$ In patients with hip osteoarthritis, exercise was associated with sustained moderate reductions in pain and improvement in physical function. ${ }^{12}$ For patients with knee osteoarthritis, there was a moderate reduction in pain and moderate improvement in physical function. ${ }^{13}$

The positive effects of exercise on hip and knee osteoarthritis are not dependent on the intensity of exercise. ${ }^{43}$ In fact, in a systematic review, any form of exercise was better than usual care for older women, with the most substantial pain and function benefits from aerobic and mind-body exercise such as tai chi. ${ }^{44}$ Similarly, aquatic exercise was associated with improved quality of life (SMD -0.25, 95\% CI -0.49 to -0.01$)$ and moderate pain reduction (SMD $-0.31,95 \% \mathrm{CI}-0.47$ to -0.15 ) in older women compared with controls. ${ }^{45}$
Patient counseling suggestion. Walking, tai chi, and water aerobics improve function and reduce pain from knee and hip osteoarthritis.

\section{Osteoporosis and fall prevention}

Falls are the fifth leading cause of morbidity and account for up to $40 \%$ of injury-related deaths in older adults. ${ }^{1}$ Older women may have multiple risk factors for falls, including decreased visual acuity, sarcopenia, postural hypotension, and frailty. A Cochrane systematic review found that physical activity significantly reduced the number of falls by $23 \%$, the number of people suffering at least 1 fall by $15 \%$, and falls requiring medical attention by $39 \% .{ }^{46}$ The average age of study participants was 76 , and $77 \%$ were women.

The beneficial effects of physical activity in fall reduction are most notable when it includes a balance component and is performed regularly. Data from community-dwelling people with a mean age of 65 or older showed a significant $39 \%$ reduction in fall rate for those performing exercises that challenged balance for more than 3 hours a week. ${ }^{19}$ Similarly, a meta-analysis of studies of tai chi, which has a balance component, found it was significantly more effective at reducing fall rates when performed at least 3 times a week compared with once a week (RR 0.36 vs 0.95).47

Osteoporosis is a significant risk factor for fall-related fracture. Strength training has consistently been shown to improve or preserve bone density at the hip in postmenopausal women, ${ }^{48,49}$ and physical activity can reduce fracture risk. ${ }^{50}$ Combined strength and aerobic training is most effective for preserving bone density at the spine in women over age 60 (SMD 0.349, 95\% CI 0.064-0.634). ${ }^{20}$ Importantly, walking by itself typically does not preserve bone density in postmenopausal women. ${ }^{49,21}$ In a systematic review of older women, exercise was associated with a significant reduction in total fracture risk (RR 0.49, 95\% CI 0.31-0.76) and vertebral fractures (RR 0.58, 95\% CI 0.35-0.95) after adjusting for quality of included studies. ${ }^{50}$

Patient counseling suggestion. Exercises that require balance, such as tai chi and yoga, prevent falls in older women. Exercising with weight or resistance bands prevents fractures.

\section{In osteoporosis, physical activity can reduce fracture risk after menopause, and strength training can preserve bone density}




\section{THE BENEFITS OF PHYSICAL ACTIVITY: TAKE-HOME MESSAGES}

The benefits of physical activity on common diseases in women age 60 and older depends on the intensity of the activity, the type of activity, the setting, and the frequency. Generally, regular physical activity of moderate to vigorous intensity is required to maximize benefit for health outcomes. Benefits include reductions in the incidence of cardiovascular disease, hypertension, diabetes, and cancer; reduced risk of stroke, falls, and death from cancer or cardiovascular disease; and fewer symptoms of depression. However, even lowlevel, low-intensity physical activity can improve diabetes-related quality of life and osteoarthritis-related pain, function, and quality of life.

The type of activity is important for reduction in the risk of osteoporosis and falls. The setting of physical activity is important for reducing hemoglobin A1c and improving COPD symptoms.

Importantly, exercise does not universally benefit the most common diseases in older women: moderate-intensity exercise does not improve LDL, walking does not significantly improve bone density, and exercise alone does not reduce the rate of dementia or mild cognitive impairment.

Physical activity benefits conditions beyond the most common causes of morbidity and death in older women. Frailty, the combination of weakness, decreased activity, slow walking speed, unintentional weight loss, and exhaustion are associated with increases in nursing home admissions, hospital length of stay, and death. Physical activity has been shown to prevent frailty, ${ }^{51}$ which in turn may prevent nursing home admissions and prolonged hospital stays.

Sarcopenia is also common in older women. Though not directly prevented by physical activity, its associated conditions, including frailty and falls, are benefited, as discussed above. Exercise-based cardiac rehabilitation benefits patients with newly diagnosed heart conditions.

\section{Selecting the exercise}

Knowing which type, intensity, and level of physical activity benefits each disease enables clinicians to make specific, accurate exercise recommendations for older women. Formulating specific recommendations for women with comorbidities is complex, requiring clinicians to consider the functional capacity and general mobility of the patient.

Exercise is a generally safe practice that benefits women of all ages. Safer forms include walking, water aerobics, and seated resistance exercises. Women desiring the health benefits of more frequent and vigorous activity should increase their activity level gradually.

Although safety is important, clinicians should recognize that functional capabilities vary widely in older women. For some women, brisk walks are challenging, whereas others can easily participate in high-intensity exercise such as tennis and group fitness classes.

By applying knowledge of the specific benefits of physical activity, clinicians can direct women to appropriate exercise resources in their community. Retirement communities and senior centers offer access to safe indoor exercise facilities for unsupervised aerobic and resistance training, as well as scheduled, supervised, mobility-appropriate exercise including line dancing, Zumba, chair yoga, water aerobics, seated strength training, and tai chi. Medicare Advantage programs also offer beneficiaries membership in exercise programs.

\section{Offer additional help}

Clinicians can further support women's physical activity goals through evidenced-based strategies such as motivational interviewing. But barriers to counseling in primary care exist related to time constraints and perceived ineffectiveness of counseling. The Exercise is Medicine campaign ${ }^{52}$ of the American Medical Association and the American College of Sports Medicine aims to overcome these barriers by providing practical, versatile, and time-effective strategies for physical activity counseling in primary care. The campaign advocates for promoting activity to every patient at every outpatient visit using 1 of 4 strategies:

- Assess current activity level using the 2-question Physical Activity Vital Sign

- Recommend exercise with optimism

- Counsel and prescribe a specific exercise plan including frequency, intensity, time, and type 
- Refer the patient to a clinical or community-based exercise professional.

Counseling provided in partnership between primary care providers and exercise professionals results in better long-term adherence and reduces time demands on practitioners. Referral to an exercise professional is an evidence-based strategy supported by the US Department of Health and Human Services. Local exercise professionals can be found using the searchable online directories from the US Registry for Exercise Professionals (http:// www.usreps.org) and the International Federation of Registers for Exercise Professionals (https://icreps.org).

\section{LIMITATIONS OF CURRENT LITERATURE ON PHYSICAL ACTIVITY}

The literature on physical activity in older women has several limitations. Large, longterm, randomized controlled trials of exercise interventions are challenging to perform. Thus, most data on exercise in primary prevention are from population-based, observational studies, which have inherent limitations. Systematic reviews and meta-analyses include studies with considerable heterogeneity, as participants are often men and women, and subgroup analyses of women participants are uncommon. Intervention lengths vary and rarely exceed 12 months. Interventions often include multiple exercise types, intensities, frequencies, and durations that are combined into broad categories such as low, moderate, and high activity levels, based on energy expenditure.

Heterogeneity in control group definition, commonly either inactive or participating in low-level physical activity, is another limitation. When low-level activity is used as the control, the observed benefits may be attenuated, as even low levels of activity have health benefits compared with inactivity.

Studies include women in a wide range of ages, from the 60 s to the 90 s. Outcomes may vary based on the participant's decade of life, and sample sizes are often too small to allow subgroup analyses of relatively young and very old participants. Lack of diversity of study participants in terms of race, ethnicity, socioeconomic status, and geographic setting limits the generalizability of the results of physical activity studies to all women.

In addition, translation of findings from the literature to clinical practice has limitations. For some women, social and environmental obstacles to regular activity exist, including characteristics of the environment, neighborhood safety, and caregiver responsibilities. For example, the benefits of hospitalbased pulmonary rehabilitation for COPD or aquatic exercise for osteoarthritis can only be realized if the patient has access to a hospital or swimming pool. Similarly, the benefits of walking can only be achieved if the environment is convenient and safe for walking. And leisure-time activity can only be pursued if adequate social support exists to allow time away from family and work responsibilities.

All of these limitations should be considered when counseling patients.

\section{FINDING THE RIGHT STRATEGY}

As the population of women over age 60 grows, it is important to identify strategies to maximize health and minimize disease burden. Physical activity benefits the most common disease states in women. Knowing the type, intensity, and level of activity needed to achieve desired health outcomes can help the clinician make specific, individualized recommendations for exercise in the context of multimorbidity, functional abilities, and available resources. Routine counseling on exercise in partnership with an exercise professional may improve the patient's level of physical activity and is strongly recommended.

\section{DISCLOSURES}

The authors report no relevant financial relationships which, in the context of their contributions, could be perceived as a potential conflict of interest.
Most data on exercise in primary prevention are from populationbased, observational studies, which have inherent limitations 


\section{PHYSICAL ACTIVITY IN OLDER WOMEN}

\section{REFERENCES}

1. World Health Organization. Report on ageing and health. Accessed June 14, 2021. https://www.who.int/ageing/events/world-report2015-launch/en/

2. US Department of Health and Human Services. Physical activity guidelines for Americans. 2nd ed. Accessed June 14, 2021. https://health.gov/sites/default/files/2019-09/Physical_Activity_ Guidelines_2nd_edition.pdf

3. Diep L, Kwagyan J, Kurantsin-Mills J, Weir R, Jayam-Trouth A. Association of physical activity level and stroke outcomes in men and women: a meta-analysis. J Womens Health (Larchmt) 2010; 19(10):1815-1822. doi:10.1089/jwh.2009.1708

4. Pescatello LS, Buchner DM, Jakicic JM, et al. Physical activity to prevent and treat hypertension: a systematic review. Med Sci Sports Exerc 2019; 51(6):1314-1323. doi:10.1249/MSS.0000000000001943

5. Smith AD, Crippa A, Woodcock J, Brage S. Physical activity and incident type 2 diabetes mellitus: a systematic review and doseresponse meta-analysis of prospective cohort studies. Diabetologia 2016; 59(12):2527-2545. doi:10.1007/s00125-016-4079-0

6. Tulloch $\mathbf{H}$, Fortier $\mathbf{M}$, Hogg $\mathbf{W}$. Physical activity counseling in primary care: who has and who should be counseling?. Patient Educ Couns 2006; 64(1-3):6-20. doi:10.1016/j.pec.2005.10.010

7. Kraus WE, Powell KE, Haskell WL, et al. Physical activity, all-cause and cardiovascular mortality, and cardiovascular disease. Med Sci Sports Exerc 2019; 51(6):1270-1281. doi:10.1249/MSS.0000000000001939

8. Sattelmair J, Pertman J, Ding EL, Kohl HW 3rd, Haskell W, Lee IM. Dose response between physical activity and risk of coronary heart disease: a meta-analysis. Circulation 2011; 124(7):789-795.

9. Pan B, Ge L, Xun YQ, et al. Exercise training modalities in patients with type 2 diabetes mellitus: a systematic review and network meta-analysis. Int J Behav Nutr Phys Act 2018; 15(1):72. doi:10.1186/s12966-018-0703-3

10. Moore SC, Lee IM, Weiderpass E, et al. Association of leisure-time physical activity with risk of 26 types of cancer in 1.44 million adults. JAMA Intern Med 2016; 176(6):816-825. doi:10.1001/jamainternmed.2016.1548

11. Mishra SI, Scherer RW, Geigle PM, et al. Exercise interventions on health-related quality of life for cancer survivors. Cochrane Database Syst Rev 2012; 2012(8):CD007566. doi:10.1002/14651858.CD007566.pub2

12. Fransen M, McConnell S, Hernandez-Molina G, Reichenbach S. Exer cise for osteoarthritis of the hip. Cochrane Database Syst Rev 2014; (4):CD007912. doi:10.1002/14651858.CD007912.pub2

13. Fransen M, McConnell S, Harmer AR, Van der Esch M, Simic M, Bennell KL. Exercise for osteoarthritis of the knee. Cochrane Database Syst Rev 2015;1:CD004376. doi:10.1002/14651858.CD004376.pub3

14. Naci H, Salcher-Konrad M, Dias S, et al. How does exercise treatment compare with antihypertensive medications? A network metaanalysis of 391 randomised controlled trials assessing exercise and medication effects on systolic blood pressure. Br J Sports Med 2019; 53(14):859-869. doi:10.1136/bjsports-2018-099921

15. de Souto Barreto P, Demougeot L, Vellas B, Rolland Y. Exercise training for preventing dementia, mild cognitive impairment, and clinically meaningful cognitive decline: a systematic review and meta-analysis. J Gerontol A Biol Sci Med Sci 2018; 73(11):1504-1511. doi:10.1093/gerona/glx234

16. Li X, Guo R, Wei Z, Jia J, Wei C. Effectiveness of exercise programs on patients with dementia: a systematic review and meta-analysis of randomized controlled trials. Biomed Res Int 2019; 2019:2308475. doi:10.1155/2019/2308475

17. Wuytack F, Devane D, Stovold E, et al. Comparison of outpatient and home-based exercise training programmes for COPD: a systematic review and meta-analysis. Respirology 2018; 23(3):272-283. doi:10.1111/resp.13224

18. Silveira H, Moraes H, Oliveira N, Coutinho ES, Laks J, Deslandes A. Physical exercise and clinically depressed patients: a systematic review and meta-analysis. Neuropsychobiology 2013; 67(2):61-68 doi: $10.1159 / 000345160$

19. Sherrington C, Michaleff ZA, Fairhall N, et al. Exercise to prevent falls in older adults: an updated systematic review and meta-analysis. Br J Sports Med 2017; 51(24):1750-758. doi:10.1136/bjsports-2016-096547

20. Zhao R, Zhang M, Zhang Q. The effectiveness of combined exercise interventions for preventing postmenopausal bone loss: a systematic review and meta-analysis. J Orthop Sports Phys Ther 2017; 47(4): 241-251. doi:10.2519/jospt.2017.6969

21. Ma D, Wu L, He Z. Effects of walking on the preservation of bone mineral density in perimenopausal and postmenopausal women: a systematic review and meta-analysis. Menopause 2013; 20(11):12161226. doi:10.1097/GME.0000000000000100

22. Huai P, Xun H, Reilly KH, Wang Y, Ma W, Xi B. Physical activity and risk of hypertension: a meta-analysis of prospective cohort studies. Hypertension 2013; 62(6):1021-1026. doi:10.1161/HYPERTENSIONAHA.113.01965

23. Byrne H, Caulfield B, De Vito G. Effects of self-directed exercise programmes on individuals with type 2 diabetes mellitus: a systematic review evaluating their effect on HBA1C and other metabolic outcomes, physical characteristics, cardiorespiratory fitness and functional outcomes. Sports Med 2017; 47(4):717-733. doi:10.1007/s40279-016-0593-y

24. Cai H, Li G, Zhang P, Xu D, Chen L. Effect of exercise on the quality of life in type 2 diabetes mellitus: a systematic review. Qual Life Res 2017; 26(3):515-530. doi:10.1007/s11136-016-1481-5

25. Albarrati AM, Alghamdi MSM, Nazer RI, Alkorashy MM, Alshowier N, Gale N. Effectiveness of low to moderate physical exercise training on the level of low-density lipoproteins: a systematic review. Biomed Res Int 2018; 2018:5982980. doi:10.1155/2018/5982980

26. Mann S, Beedie C, Jimenez A. Differential effects of aerobic exercise, resistance training and combined exercise modalities on cholesterol and the lipid profile: review, synthesis and recommendations. Sports Med 2014; 44(2):211-221. doi:10.1007/s40279-013-0110-5

27. Stout NL, Baima J, Swisher AK, Winters-Stone KM, Welsh J. A systematic review of exercise systematic reviews in the cancer literature (2005-2017). PM R 2017; 9(9S2):S347-S384 doi:10.1016/j.pmrj.2017.07.074

28. Zhang $X$, Li Y, Liu D. Effects of exercise on the quality of life in breast cancer patients: a systematic review of randomized controlled trials. Support Care Cancer 2019; 27(1):9-21. doi:10.1007/s00520-018-4363-2

29. Bekhet AH, Abdallah AR, Ismail HM, et al. Benefits of aerobic exercise for breast cancer survivors: a systematic review of randomized controlled trials. Asian Pac J Cancer Prev 2019; 20(11):3197-3209. doi:10.31557/APJCP.2019.20.11.3197

30. Beckett MW, Ardern Cl, Rotondi MA. A meta-analysis of prospective studies on the role of physical activity and the prevention of Alzheimer's disease in older adults. BMC Geriatr 2015; 15:9. doi:10.1186/s12877-015-0007-2

31. Gheysen F, Poppe L, DeSmet A, et al. Physical activity to improve cognition in older adults: can physical activity programs enriched with cognitive challenges enhance the effects? A systematic review and meta-analysis. Int J Behav Nutr Phys Act 2018; 15(1):63. doi:10.1186/s12966-018-0697-x

32. Law CK, Lam FM, Chung RC, Pang MY. Physical exercise attenuates cognitive decline and reduces behavioural problems in people with mild cognitive impairment and dementia: a systematic review. J Physiother 2020; 66(1):9-18. doi:10.1016/j.jphys.2019.11.014

33. de Almeida SIL, Gomes da Silva M, Marques ASPD. Home-based physical activity programs for people with dementia: systematic review and meta-analysis. Gerontologist 2020; 60(8):600-608. doi:10.1093/geront/gnz176

34. Robles PG, Brooks D, Goldstein R, Salbach N, Mathur S. Gender-associated differences in pulmonary rehabilitation outcomes in people with chronic obstructive pulmonary disease: a systematic review. J Cardiopulm Rehabil Prev 2014; 34(2):87-97. doi:10.1097/HCR.0000000000000018

35. Li W, Pu Y, Meng A, Zhi X, Xu G. Effectiveness of pulmonary reha- 


\section{CHAVEZ AND COLLEAGUES}

bilitation in elderly patients with COPD: a systematic review and meta-analysis of randomized controlled trials. Int J Nurs Pract 2019; 25(5):e12745. doi:10.1111/ijn.12745

36. McCarthy B, Casey D, Devane D, Murphy K, Murphy E, Lacasse Y. Pulmonary rehabilitation for chronic obstructive pulmonary disease. Cochrane Database Syst Rev 2015; (2):CD003793. doi:10.1002/14651858.CD003793.pub3

37. Ngai SP, Jones AY, Tam WW. Tai Chi for chronic obstructive pulmonary disease (COPD). Cochrane Database Syst Rev 2016; (6):CD009953. doi:10.1002/14651858.CD009953.pub2

38. Gendron LM, Nyberg A, Saey D, Maltais F, Lacasse Y. Active mindbody movement therapies as an adjunct to or in comparison with pulmonary rehabilitation for people with chronic obstructive pulmonary disease. Cochrane Database Syst Rev 2018;10(10):CD012290. doi:10.1002/14651858.CD012290.pub2

39. Cooney GM, Dwan K, Greig CA, et al. Exercise for depression. Cochrane Database Syst Rev 2013;(9):CD004366 doi:10.1002/14651858.CD004366.pub6

40. Bridle C, Spanjers K, Patel S, Atherton NM, Lamb SE. Effect of exercise on depression severity in older people: systematic review and meta-analysis of randomised controlled trials. Br J Psychiatry 2012 201(3):180-185. doi:10.1192/bjp.bp.111.095174

41. Sjösten N, Kivelä SL. The effects of physical exercise on depressive symptoms among the aged: a systematic review. Int J Geriatr Psychiatry 2006; 21(5):410-418. doi:10.1002/gps.1494

42. Kuss K, Becker A, Quint S, Leonhardt C. Activating therapy modalities in older individuals with chronic non-specific low back pain: a systematic review. Physiotherapy 2015; 101(4):310-318. doi:10.1016/j.physio.2015.04.009

43. Regnaux JP, Lefevre-Colau MM, Trinquart L, et al. High-intensity versus low-intensity physical activity or exercise in people with hip or knee osteoarthritis. Cochrane Database Syst Rev 2015; (10):CD010203. doi:10.1002/14651858.CD010203.pub2

44. Goh SL, Persson MSM, Stocks J, et al. Relative efficacy of different exercises for pain, function, performance and quality of life in knee and hip osteoarthritis: systematic review and network meta-analysis. Sports Med 2019; 49(5):743-761. doi:10.1007/s40279-019-01082-0

45. Bartels EM, Juhl CB, Christensen R, et al. Aquatic exercise for the treatment of knee and hip osteoarthritis. Cochrane Database Syst Rev 2016; 3:CD005523. doi:10.1002/14651858.CD005523.pub3

46. Sherrington C, Fairhall NJ, Wallbank GK, et al. Exercise for preventing falls in older people living in the community. Cochrane Database Syst Rev 2019; 1(1):CD012424. doi:10.1002/14651858.CD012424.pub2

47. Huang ZG, Feng YH, Li YH, Lv CS. Systematic review and metaanalysis: tai chi for preventing falls in older adults. BMJ Open 2017; 7(2):e013661. doi:10.1136/bmjopen-2016-013661

48. Howe TE, Shea B, Dawson LJ, et al. Exercise for preventing and treating osteoporosis in postmenopausal women. Cochrane Database Syst Rev 2011; (7):CD000333. doi:10.1002/14651858.CD000333.pub2

49. Gómez-Cabello A, Ara I, González-Agüero A, Casajús JA, Vicente-Rodríguez $\mathbf{G}$. Effects of training on bone mass in older adults: a systematic review. Sports Med 2012; 42(4):301-325. doi:10.2165/11597670-000000000-00000

50. Kemmler W, Häberle L, von Stengel S. Effects of exercise on fracture reduction in older adults: a systematic review and meta-analysis. Osteoporos Int 2013; 24(7):1937-1950. doi:10.1007/s00198-012-2248-7

51. Oliveira JS, Pinheiro MB, Fairhall N, et al. Evidence on physical activity and the prevention of frailty and sarcopenia among older people: a systematic review to inform the World Health Organization Physical Activity guidelines. J Phys Act Health 2020; 1-12. doi:10.1123/jpah.2020-0323

52. American College of Sports Medicine. Exercise is medicine. Accessed June 14, 2021. https://www.exerciseismedicine.org/

Address: Augustine Chavez, MD, Department of Family Medicine, Mayo Clinic, 13737 North 92nd Street, Scottsdale, AZ 85260

chavez.augustine@mayo.edu 